The Geneva Papers on Risk and Insurance, 18 (No. 69, October 1993), 403-411

\title{
Quantitative Accumulation - Qualitative Jump New Social Challenges Facing the Insurance Industry
}

\author{
by Peter Frey*
}

\section{Preliminary remarks}

It was Hegel who coined the phrase used in the title of this article, namely of quantitative accumulation and qualitative jump. 160 years after Hegel's death and three years after the fall of the Berlin Wall it is high time to rehabilitate his original idea, an idea which, misappropriated by Karl Marx to justify the revolution of the working class, has fallen into disrepute.

For as we now know, the adoption of Hegel's idea could not prevent the flagrant falsification of Marx's hypotheses in that large-scale real-life test called Eastern Europe. Hegel's phrase, however, perfectly fits the current situation of the insurance industry - a parallel which, we may rightly assume, would at the time have seemed highly improbable both to the man who coined the phrase and to the one who misappropriated it.

\section{Quantitative accumulation}

In 1987 direct insurance premiums worldwide passed the $\$$ US 1,000 billion marks for the first time. By 1990 the total was already $\$$ US 1,355 billion. This is an impressive figure and pretty close to the total gross national product of the Federal Republic of Germany, the third largest country worldwide in terms of GNP.

Figure 1 shows continuing growth, with the growth rates themselves increasing in recent years. Even if these figures were expressed in real terms - i. e. in 1990 prices - we would arrive at a quite substantial absolute figure of $\$$ US 127 billion and an impressive average growth rate of $5.5 \%$. If one were to take a linear rather than a logarithmic scale to illustrate premium volume growth, the result would be a curve reminiscent of the one depicting the population explosion. Now we have all been aware since being initiated into the world of cybernetics that a phenomenon we all hope and strive for, to wit, economic growth (at the highest possible rate) is, horribile dictu, doomed to crack, at least in its exponential form. The lemmings appear on the scene and visions of an 'overgrazed' world are not far behind; and we all know what the consequences of positive feedbacks are.

* Mitglied der Konzernleitung, Schweizerische Rückversicherungs-Gesellschaft, Zürich. The author would like to thank Thomas Holzheu and Dr. Wulf Walter for their assistance in preparing this article. 
Fig. 1: Direct insurance premiums worldwide

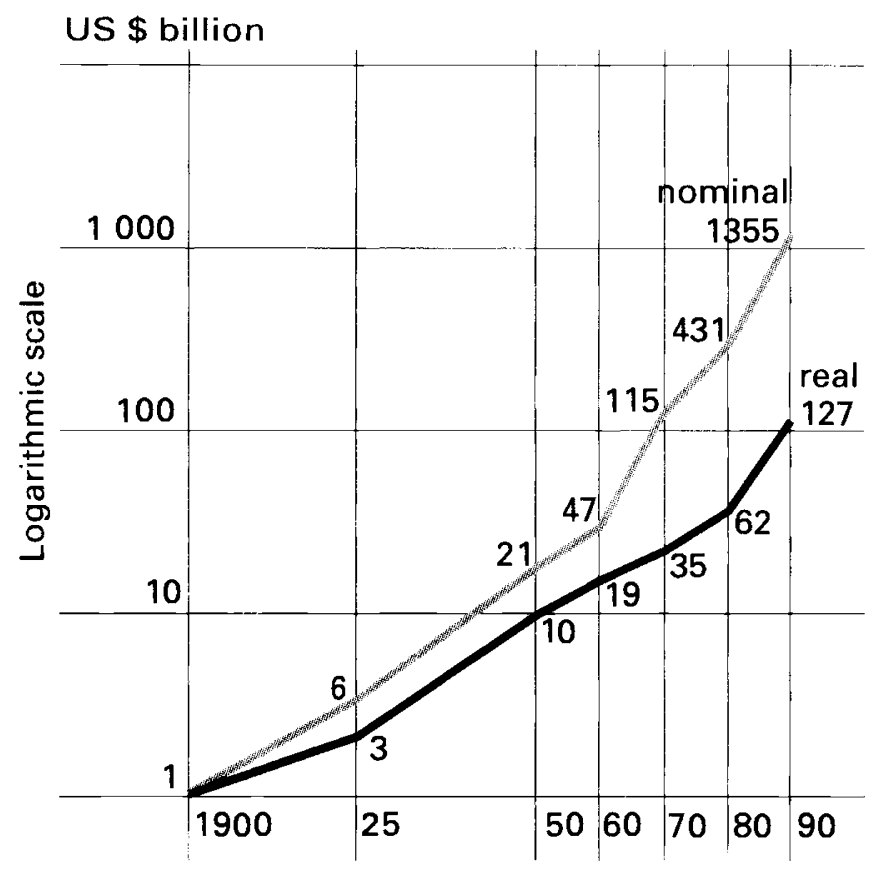

1990: 1355 US \$ billion

Bayerische Rück

MS/08-1192-sou

Are we already in the process of 'overgrazing' our markets? Proposition 103 in California might in fact be seen as a local symptom of just this. Proposition 103 was a referendum held in California in conjunction with the US presidential elections of 1988. The 'proposition' was that motor third party insurance premiums should be reduced across the board by $20 \%$. This is truly remarkable since it shows that society does not see insurance companies as redistribution systems which share the burden of losses evenly over all available shoulders, as is the basic principle of insurance. Proposition 103 instead demonstrates that, at least in California, insurance companies are regarded as risk specialists, whose duty is to see that the costs of risk - in this case, motor third party insurance - do not go through the roof. Apparently, premiums that exceed certain levels are unacceptable, e. g. if it costs more to insure a car than the car itself is worth. Although there are certain signs of overgrazing at a local level, for the international scene the assumption probably does not hold true, and we may rather proceed on the supposition that the insurance industry, precisely because of cybernetic correlations, is certain to experience ongoing growth. There are three main reasons for this supposition: the continuing trend towards individualization; the increase in risk potential; and - not entirely unrelated - the high income elasticity of insurance. 


\subsection{Monetization of traditional security systems in the course of increasing individualization}

In the Middle Ages villagers were insured without having to be customers of an insurance company. If a person's property was damaged by fire or he/she suffered some other great misfortune, that person's immediate or extended family, the neighbourhood, or in some cases even the whole village would step in to hclp out. Of course this solidarity in times of need was not without its price: cvery member of a community was expected to conform to that community's code of behaviour, a code sanctioned by social control - often from the pulpit.

Paying premiums does not necessarily guarantee more protection, rather it functions as a surrogate for traditional security systems such as the family and the clan. In the course of society's advancement and of the accompanying processes of differentiation and individualization, security services hitherto provided by the collective and often in the form of nonmonetary obligations have bcen devolved upon privatc-enterprise institutions. A part of the worldwide growth in premiums, thcrefore, can be attributed to this monetization of traditional security systems, and going by what we know, an end to this process is nowhere in sight. Thus, in future, book transfers, as it were, will continue to occur on the macroeconomic balance sheet from 'non-monetary services by households' to 'purchased services'. This is all the more likely since the process in question is closely linked to growing personal freedoms, with the liberation of the individual 'from the network of economic and moral dependences' (Ewald, 1989, p. 386).

\subsection{Increase in risk potential}

The more a society develops, the more the risks inherent in that society increase too. True, dangers to life and health decrease, as the increase in life expectancy not only in the industrialized world but also in developing countries shows (in the latter, average life expectancy has risen by 15 years since 1950 ). The absolute increase in the world population, however, generates in itself a constant increase in the demand for insurance, since it is not only our lives and health which are exposed to danger but also our material goods. The amount of wealth determines the potential risk, which is why a society's exposure rises with its affluence. This correlation becomes clear at once if we compare the fittings and furnishings in the houses of our - for the most part - rustic ancestors with those of our modern households.

\subsection{High income elasticity of insurance}

The third reason for the sustaincd quantitative accumulation is the high degree of elasticity to be observed on insurance markets worldwide (sec Fig. 2). Since 1950 expenditure on insurance has been increasing faster than gross domestic product.

This correlation - commonly known as the income clasticity of demand for insurance cover - produces, in combination with radical differences in the economic development of various countries and groups of countrics, perspectives for the future of insurance which, bccausc of their magnitude and dynamics, must themselves give cause for concern (sec Fig. 3).

Relating the share of insurance premiums in a country's GDP (vertical axis) to that country's per-capita GDP (horizontal axis), we typically get four clusters of countrics: on the very bottom left the devcloping countries (more precisely, the Least Developed Countrics - LDCs); above them the NICs (Newly Industrialized Countries); to the right of the 
Fig. 2: Insurance premiums as percentage of GDP 1950-1990, Germany

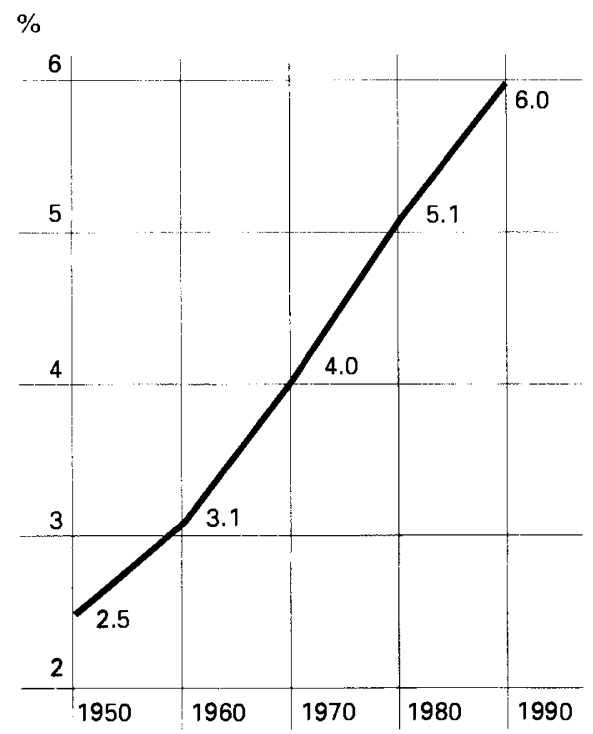

Bayerische Rück

MS/10-1192-sou

Fig. 3: Increasing significance of insurance in the process of economic development

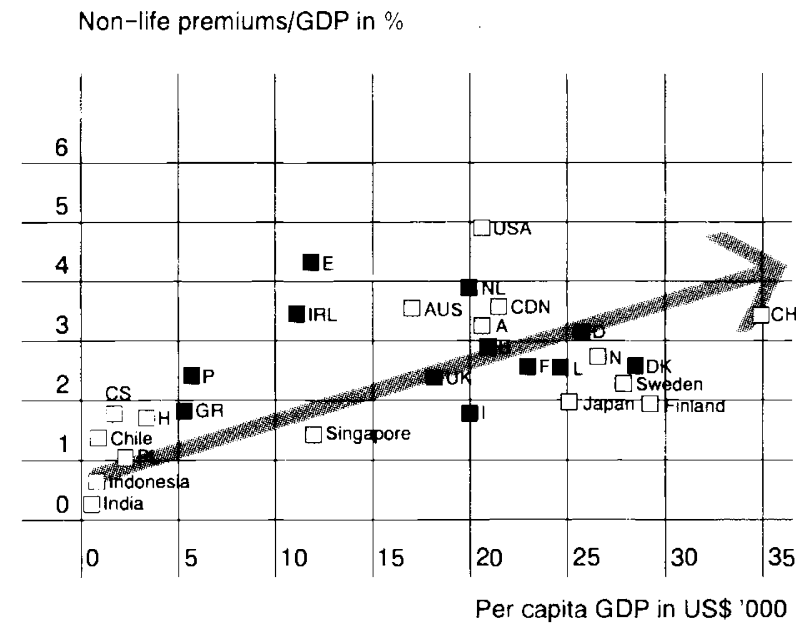

Bayerische Rück 
arrow the countries comprising the former Eastern Bloc; and finally, on the upper right, the group of industrialized countries with market economies, which - notwithstanding some discrepancies in the reporting of insurance services - shows a considerable spread depending on level of development and national peculiarities.

The graph reveals that relative expenditure on insurance rises with per-capita income. This may almost be regarded as a truism for the development of individual countries but, when seen in an international comparison, it certainly prompts further conclusions. If we assume, for instance, that the market-economy model will continue to gain ground worldwide, almost exciting prospects are opened up for the international insurance industry. For not only will the currently underdeveloped clusters tend to push themselves upwards and to the right, the developed countries will continue to improve their position, with the result that insurance premiums worldwide will continue to increase at a higher rate than incomes. Of course, this trend cannot continue ad infinitum; otherwise a point would be reached at some time in the future when total GDP is spent on insurance. For the foreseeable future, however, the insurance density will continue to increase, our markets continue to expand - initially at least a purely quantitative process which, however, so the theory goes, will have lasting qualitative implications.

\section{Qualitative jump}

François Ewald propagates the 'insurance society' because, he says, 'insurance constitutes the real core of modern societies' (Ewald, 1989, p. 385). Ewald thus describes what, at least for the time being, may be regarded as the last link in a well-known chain, which began with agrarian society and ended, until the introduction of Ewald's term, with Ulrich Beck's 'risk society' (see Fig. 4).

Fig. 4: Insurance on the way from a necessary evil to a key industry

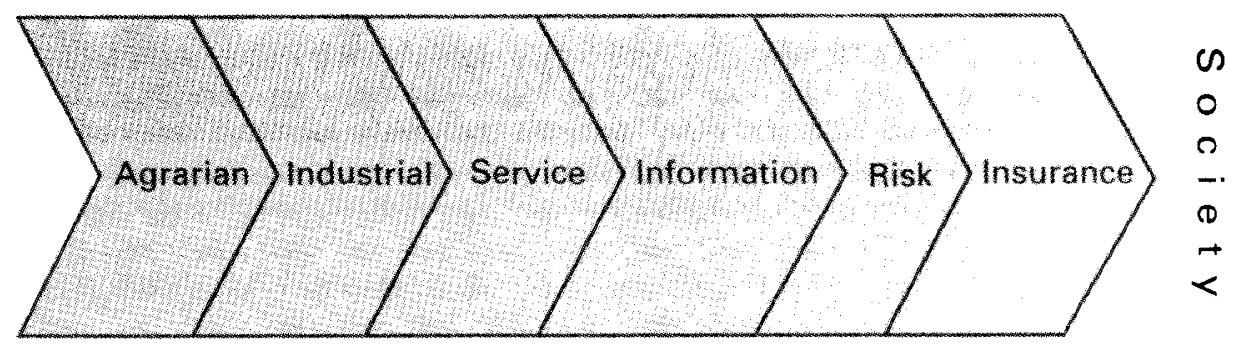

Bayerische Rück

MS/13-1192-sou

The metamorphosis of insurance from 'quantitative accumulator' to the performer of more highly qualified functions is heralded and accompanied by mental processes. It is first of all necessary to modify our traditional risk concept; then the rules of the insurance industry's own 'inner games', as it were, must be rewritten. What this means above all is redefining our view of the function of insurance, the notion of 'uninsurability' and the insurance industry's field of enterprise. 


\subsection{Changes of paradigm}

The term 'risk' traditionally has a negative connotation. It is equated with 'danger', which ought to result in our avoiding risks where possible and make us feel best when our personal risk factor is zero.

An examination of the behaviour patterns of both individuals and institutions, however, shows that such aversion to risk is by no means always the case. The Titanic sank because it was thought to be unsinkable, and the rebate initially given by German motor insurers for cars equipped with anti-lock braking systems had hardly been introduced before it was dropped again.

Clearly, then, the concept of 'risk' involves a component other than just 'danger'. This is the element of 'chance' or 'opportunity', as expressed in the Chinese word for risk, 'weiji'. Wei-ji is composed of the characters for 'danger' and 'chance'. Thus, what is immediately clear to the Chinese can be understood by speakers of European languages only after a thoroughgoing study of uncertainty. If we have learnt our lesson from Asia well, we must arrive at an approach which allows us to perceive the opportunities contained in risks at least as strongly as the inherent dangers.

So much for the first change of paradigm. The second can be observed with regard to the function of insurance. The function of insurance has traditionally been seen as the 'production of security': actuarial calculations, the spreading of risks throughout the collective and, conversely, the atomization of risks are all employed to achieve a process of consolidation, which makes stochastically independent risks shrink in magnitude to a fraction of what they would have been without insurance.

From a conventional standpoint this relationship ean be described as follows. If we start with a level of risk of 100 units, this 'gross' risk can be reduced through insurance by, for example, 30 units so that the remaining net risk is 70 units. This traditional function of insurance produces a welfare dividend in that the individual or institution is exposed to a smaller risk.

On the other hand, H,-W. Sinn, Professor of Economics at the University of Munich, was probably the first to describe insurance as an institution 'which multiplies the production factor "risk" (Sinn, 1986, p. 564), since individuals with insurance cover tend to increase their personal exposure and thus the overall level of risk in society.

Expressed in graph form, this behaviour can be seen to increase the gross risk from 100 to 130 units so that, after insurance, the result is again a net risk of 100 , This theory of risk homeostasis maintains that there is a constant predilection for risks and that if risks are reduced through insurance, ever greater gross risks will be taken.

Returning to the two examples given above, we can see that in both cases those responsible took on risks which they would not have accepted had there not been additional safety measures of a technical nature. According to the theory, then, insurance has the same effect as such technical safety measures: it makes a risk more acceptable.

Both changes of paradigm render the insurance industry's long established patterns of behaviour obsolete. Whereas previously insurers could calmly assess the risks offered to them according to the principle of insurability and, where necessary, reject them as uninsurable, they must now accept the criticism that they bear considerable responsibility for the creation of those risks they now label as uninsurable. It seems that, for better or 
worse, the insurance industry has to shoulder this responsibility, which is the inevitable result of the changing perception of its own function in society, and must enter into the societal discussion of risks more actively than it was hitherto wont to do.

\subsection{New limits of insurability}

It goes without saying that it is not expedient for the insurance industry to accept each and every risk. The actuarial spreading of risk over time and space can only be successful if the cover is clearly defined and sufficient data are available as a basis for calculation. Often, however, it is precisely these prerequisites which are lacking, e.g. in the case of environmental or US products liability risks. Here, effective market solutions are impeded by market mismatches due to asymmetrical information flows (e.g. moral hazard and adverse selection), i.e. the behaviour of the insureds can actively influence the scale of the loss. There seems to be no alternative but to exclude such risks as uninsurable.

In spite of this, the limits of insurability are constantly being pushed outwards; more and more risks are becoming insurable. The best example of this is to be found precisely in the field of environmental liability insurance in a number of European countries. The market for insurance solutions as a whole is expanding to embrace new risks. Further examples might be cited, such as satellite insurance, interdependency losses in business interruption insurance, or "personal assistance" insurance, the scope of cover under which it is constantly being extended. But while we are rightly proud to recognize in this an expression of the industry's own innovative powers, this should not blind us to the fact that innovation should almost be a matter of course in our world of growth, structural change and dynamism.

And how do things look beyond the limits of insurability? Does our social function lapse at the point where loss-free insurance policies cease to be possible? The answer must be sought in the industry's own perception of its field of enterprise.

\subsection{The insurer's field of enterprise is not the 'insurance market' but the 'risk market'}

Unlike the private railway companies in America, who failed to realize - until it was too late - that they were not in the 'railway' but in the 'transport' business, insurance companies are increasingly coming to appreciate that their field of enterprise is not the 'insurance market', but the 'risk market' (see Fig. 5).

Bavarian Re, for instance, has founded AssTech Risk Management GmbH, whose scope of business is not insurance or reinsurance in a strict sense, but risk services going far beyond the simple conclusion of insurance contracts. Bavarian Re was by no means the first company to play an active role in this field, even though the first volume of our publication 'Society and Uncertainty' was in fact in the forefront in setting this trend, a trend which is continued by this year's sequel 'Risk is a Construct'. Of the many activities and newly founded companies/institutions in this field, the following deserve special mention: the Allianz Technology Centre; the famous Fire Offices' Committee's Laboratory in Borehamwood, UK (quite an early contribution in this context): the Gerling World Institute; the same company's very appropriately named 'Risk Academy'; the joint project 'Assekuranz 2000' led by Mathias Haller in St Gallen; the Volksfürsorge Academy, with a remarkably broad spectrum of activities as regards risks and development; and, a further Allianz project, the recently established Foundation for Environmental Protection. All these activities, in my opinion, justify the use of the term 'qualitative jump' for the insurance industry. It is a jump which is not yet in the landing phase, has perhaps not even reached its vertex. But one thing is certain: the jump will take us a long way. 
Fig. 5: Risk market

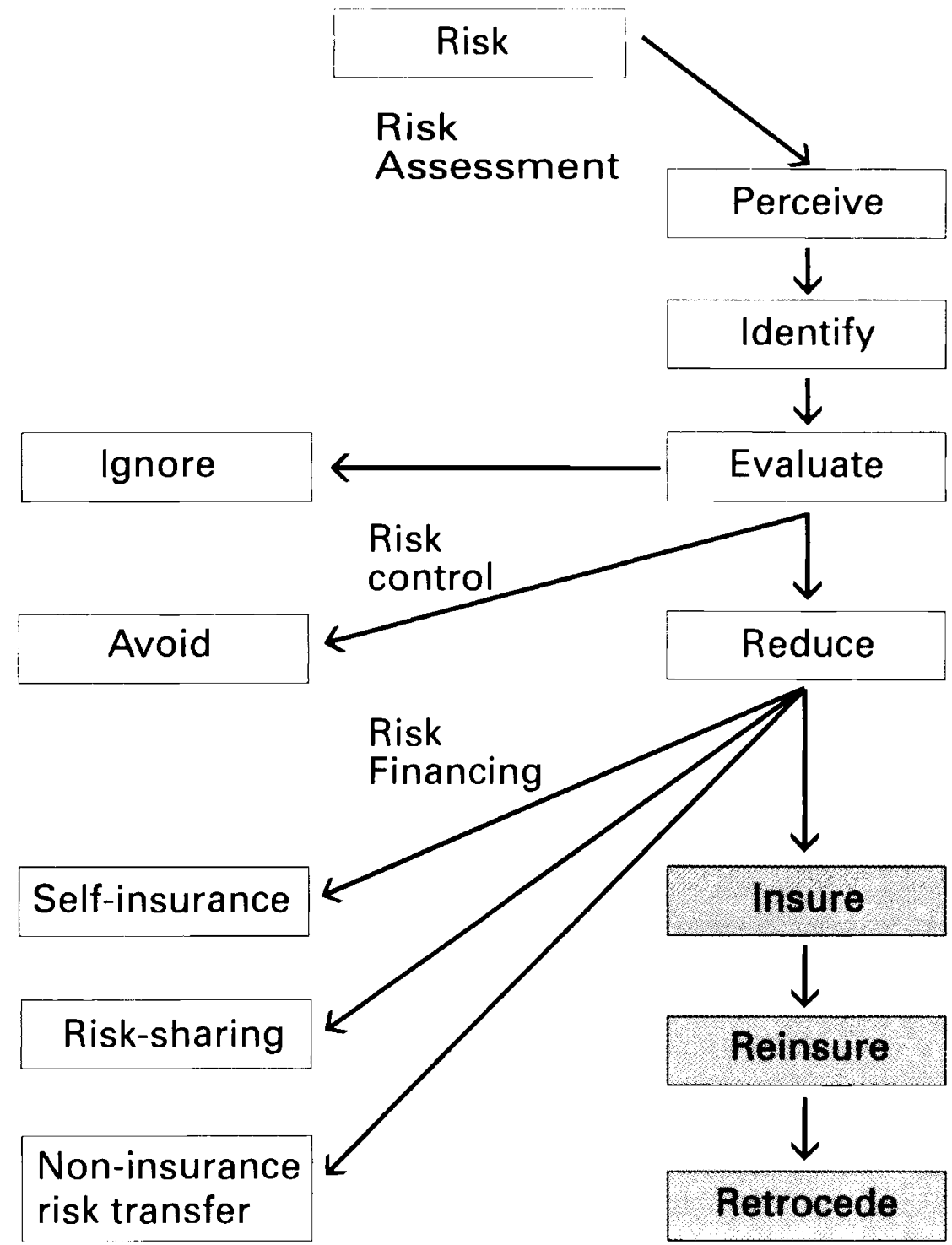

Bayerische Rück 


\section{Concluding remarks}

The qualitative jump is well suited to overcoming the frequently bemoaned incongruence between the insurers' image of themselves and how they are seen by others. The more the insurance industry is able - by extending its activities beyond the field of the traditional insurance market - to provide additional risk services (particularly with regard to risk perception and loss prevention), the closer the industry will come to fulfilling the public's expectations of its risk specialists. This, however, is not likely to put an end to the often unedifying discussion of the insurance industry's image and its level of acceptance in society. Rather the discussion would continue with more vehemence but in a positive manner.

\section{REFERENCES}

Bayerische Rückversicherung (ed.), Society and Uncertainty, Karlsruhe 1987.

EWALD, F., Die Versicherungs-Gesellschaft, in: Kritische Justiz, 22/1989, pp. 385-393.

FREY, P. and WALTER, W., Beitrag der Versicherung zur Bewältigung von Existenzrisiken der Gesellschaft, in: Zeitschrift für die gesamte Versicherungswissenschaft, 3/1988, pp. 363-383.

Schweizerische Rückversicherungs-Gesellschaft, Sigma, 1979-1990, Zurich.

SINN, H.-W. Risiko als Produktionsfaktor, in: Jahrbuch für Nationalökonomie und Statistik, Stuttgart 1986 .

The original German version of this article appeared in: Hopp, F.W. and MEHL, G. (eds.), Versicherungen in Europa heute und morgen, Karlsruhe 1991. 